University of Nebraska - Lincoln

DigitalCommons@University of Nebraska - Lincoln

Architectural Engineering -- Faculty Publications

Architectural Engineering and Construction,

Durham School of

$1-2020$

\title{
Investigating Multidimensional Characteristics of Noise Signals with Tones from Building Mechanical Systems and Their Effects on Annoyance
}

Joonhee Lee

University of Nebraska - Lincoln, Joonhee.Lee@concordia.ca

Lily M. Wang

University of Nebraska - Lincoln, Iwang4@unl.edu

Follow this and additional works at: https://digitalcommons.unl.edu/archengfacpub

Part of the Architectural Engineering Commons, Construction Engineering Commons, Environmental Design Commons, and the Other Engineering Commons

Lee, Joonhee and Wang, Lily M., "Investigating Multidimensional Characteristics of Noise Signals with Tones from Building Mechanical Systems and Their Effects on Annoyance" (2020). Architectural Engineering -- Faculty Publications. 174.

https://digitalcommons.unl.edu/archengfacpub/174

This Article is brought to you for free and open access by the Architectural Engineering and Construction, Durham School of at DigitalCommons@University of Nebraska - Lincoln. It has been accepted for inclusion in Architectural Engineering -- Faculty Publications by an authorized administrator of DigitalCommons@University of Nebraska Lincoln. 


\title{
Investigating multidimensional characteristics of noise signals with tones from building mechanical systems and their effects on annoyance
}

Durham School of Architectural Engineering and Construction, University of Nebraska-Lincoln, Omaha, Nebraska 68182, USA

\begin{abstract}
:
This paper investigates multidimensional characteristics of tonal noise from heating, ventilation, and air-conditioning systems, besides loudness and tonality, to improve prediction of annoyance. Two studies were conducted: multidimensional scaling (MDS) analysis to determine what other perceptual signal characteristics are important and perceptual weight analysis (PWA) to understand the impact of multiple tones in a signal. In the MDS study, paired comparison tasks were conducted to gather similarity and annoyance data. Results show that the latent perceptual dimensions are related to the signal's tonality, loudness, sharpness, and roughness. Including metrics for these perceptions, except roughness, improves the performance of earlier annoyance prediction models. Including both sharpness and tonal audibility does not further improve prediction performance, though. In the PWA study, noise stimuli with five-tone complexes between $125 \mathrm{~Hz}$ and $2 \mathrm{kHz}$ were generated for subjective testing to obtain a perceptual weighting function. The levels of each tone were randomly adjusted for every trial, and both harmonic and inharmonic tone complexes were utilized. The PWA result was applied as a spectral weighting function to calculate a proposed weighted-sum tonal audibility metric. Utilizing the proposed metric instead of the traditional tonal audibility metric improves annoyance prediction to a similar degree as including sharpness. (C) 2020 Acoustical Society of America.
\end{abstract}

https://doi.org/10.1121/10.0000487

(Received 20 June 2018; revised 27 November 2019; accepted 2 December 2019; published online 17 January 2020)

[Editor: Kirill V. Horoshenkov]

Pages: 108-124

\section{INTRODUCTION}

This paper presents two subjective investigations using noise with tones produced by building mechanical systems, specifically heating, ventilation, and air-conditioning (HVAC) systems. Many previous studies, including the authors' previous works (Lee et al., 2017; Lee and Wang, 2018; Oliva et al., 2017; Ryherd and Wang, 2008), used only artificially synthesized noise stimuli and/or a few actual recordings depending on the objectives of the studies. These studies confirmed that more tonal noises lead to more annoyed responses, but they neglected the effect of other sound characteristics, such as spectral or temporal characteristics of tones, as the studies utilized a single tone frequency added to broadband noises mostly. The findings have a limitation to be applied with complex and actual HVAC noises. The previous studies also only utilized the existing tonality metrics, which analyze the tones individually. The current tonality metrics can result in inaccurate prediction of annoyance because the metrics do not incorporate the spectral and cumulative effect of multiple tones on annoyance. Thus, this paper aims to identify sound quality characteristics of HVAC noise crucial to annoyance judgment and include those characteristics to improve the annoyance regression model developed in the previous

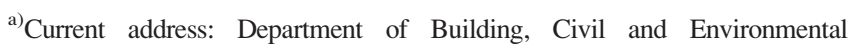
Engineering, Concordia University, 1515 Rue Sainte-Catherine O, Montreal, Quebec H3G 2W1, Canada. Electronic mail: Joonhee.Lee@concordia.ca studies (Lee et al., 2017; Lee and Wang, 2018) by utilizing assorted audio recordings from building mechanical equipment.

The first study utilizes multidimensional scaling (MDS) analysis to investigate what components, besides loudness and tonality, are of perceptual importance to listeners exposed to HVAC system noise with tones. Then, the following study using perceptual weight analysis (PWA) seeks to understand the annoyance of noise signals with multitone complexes, which can be found in many building mechanical noises. A series of paired comparison tasks are conducted, and the results are used to improve the accuracy of a proposed prediction model that links loudness and tonality metrics with annoyance judgments.

HVAC systems produce tonal noise that can result in annoyance, greater likelihood to complain, and reduction of performance such as taking longer times to complete tasks accurately (Lee et al., 2017; Lee and Wang, 2018). Developing a model to predict the perceived annoyance or likelihood to complain from a given HVAC tonal noise signal is beneficial as it can be used by manufacturers and designers of HVAC equipment and systems to understand the impact such noise can have in the built environment. Previous prediction models for HVAC tonal noise have typically focused on including only loudness and tonality, though (Hellman, 1985; More and Davies, 2010; Oliva et al., 2017).

Other works on tonal noise from machinery, products, and aircraft have sought to incorporate multidimensional 
aspects of the perceived noise. Lee et al. (2005) compared harmonic complexes in machinery against single tones, seeking to equalize perceived tonalness between harmonic complexes and single tones. Hasting et al. (2003) pointed out the effect of frequency-modulated tones in a product's noise on inaccurate estimation of tonalness. For aircraft noise, temporal characteristics like onset rates (Wang et al., 2015) and fluctuation (Paté et al., 2017) have been found to affect listeners' perception of unpleasantness, in addition to noise levels. More recently, Töpken et al. (2015, 2018) found that spectral content of sounds (i.e., a ratio of fundamental frequencies in multi-tone sounds) is generally a significant perceptual aspect that influences listener pleasantness or preference evaluations. In this paper, subjective investigations using MDS and PWA methods provide information on other multidimensional characteristics of HVAC tonal noise, which are subsequently included in revised annoyance prediction models, besides loudness and tonality to determine if the predictive performance improves significantly.

The MDS analysis technique has been used often in sound quality research. This method can be utilized to identify how subjects evaluate noise signals with a number of unknown perceptual dimensions (Kruskal, 1964). These unknown perceptual dimensions form the latent basis for a person to evaluate the sound quality of noises (Woodcock et al., 2014). Subjects are usually asked to judge how similar a pair of sound stimuli is or how preferable one of the pair is over the other. The proximity data from the similarity question and/or the dominance data from the preference question are organized in matrix form for all pairs of stimuli. Then, the number of dimensions can be determined by measuring the goodness-of-fit of a solution applied to the response matrix. MDS analysis is beneficial for investigating the relation between sound stimuli and unidentified perceptions, but one of the challenges with the MDS technique is interpreting what each dimension is. Usually, additional correlation analyses are required for this work.

The MDS technique has been used in psychoacoustic and noise research areas to investigate the annoyance by railway-induced groundborne vibration (Woodcock et al., 2014), car interior noises (Bisping, 1997; Choe, 2001), timbre perception of musical instruments (Grey and Gordon, 1978), and concert hall acoustics (Bradley and Wang, 2010). Berglund et al. (2002) investigated perception of environmental noises, including ventilation-like noise spectra, with the MDS methodology and found that spectral contrast, which is related to tonality, is the best acoustic candidate for explaining individual variances of similarity and preference judgments of the noises. Susini et al. (2004) analyzed indoor air-conditioning unit sound quality by MDS analysis. They found that the sound quality of the airconditioning units was based on three perceptual dimensions. These were significantly correlated with loudness, spectral centroid, and noise-to-harmonic ratio (NHR). The spectral centroid is related to the "brightness" of the sound perception and can be determined by the distribution of harmonics in the spectrum. The NHR is the ratio of broadband noise components to harmonic components and is related to the tonal strength of the noise signal. Listener annoyance significantly changed as these parameters varied. In the first part of this paper, MDS has been applied to noises produced by assorted types of HVAC systems, including compressors, pumps, fans and chillers, which often contain significant tonal components.

A second investigation using PWA aims to understand the relative weights of different tonal combinations. PWA can provide the relative weights of each component of perceptual features, such as loudness, from a trial-by-trial analysis. While varying the level or magnitude of some components randomly, subjects are asked to choose the noise stimulus from a pair based on loudness judgments. Correlation analysis between variations of each component and the responses then provides the relative weighting of components. PWA has often been used to investigate spectral components (Jesteadt et al., 2014; Leibold et al., 2007) or temporal components (Oberfeld et al., 2012) of complex noises contributing to overall loudness. PWA has not been widely applied, though, to noise annoyance studies. Dittrich and Oberfeld (2009) adopted this method in their investigation on annoyance and loudness of temporally varying stimuli. They found that temporal weighting improved the prediction of loudness and annoyance, and the annoyance responses were significantly different from the loudness responses.

The two studies discussed in this paper attempt to understand what other perceptual aspects of building mechanical system noise besides loudness and tonality may affect annoyance and how they interact to each other in terms of the noise-induced annoyance. Results are used to improve an annoyance model developed in the previous studies (Lee et al., 2017; Lee and Wang, 2018) by incorporating other acoustic characteristics.

\section{STUDY 1: MDS ANALYSIS OF HVAC NOISE SIGNALS}

\section{A. Participants}

Twenty adults (ten females, ten males) were paid to participate in the MDS study. They were recruited mainly from the University of Nebraska at Omaha campus. The average age of the participants was 23.9 years with a standard deviation of 4.5 years. All participants had hearing thresholds better than $25 \mathrm{~dB}$ hearing level (HL) from 125 to $8000 \mathrm{~Hz}$ for both ears.

\section{B. Stimuli}

Fifteen audio recordings from operating building mechanical equipment and three artificially synthesized signals were used in this laboratory experiment. Assorted building mechanical equipment was included to have a wide range of noise stimuli in the tests. The three artificially synthesized signals were broadband stimuli without tonal components; two of these followed the neutral room criteria 
contours of RC-38 and RC-51 (Blazier, 1981). The third stimulus had levels that were $12 \mathrm{~dB}$ higher in the $125 \mathrm{~Hz}$ octave band, above the RC-38 neutral contour, giving a rumbly impression without any tonal components. The sound levels of all signals were manually adjusted to be in the range of 45-60 dBA while maintaining the relative frequency spectrum. The tonality of the noise signals ranged from barely heard to prominent according to tonal audibility criteria (ISO, 2007). A few of them contained only a single tone characteristic, while others had fluctuating tonal characteristics, harmonic spectra, or inharmonic complex tone spectra. The sampling rate of the signals in this test was $96 \mathrm{kHz}$ and played for $5 \mathrm{~s}$.

Table I lists each signal by its noise source, $A$-weighted equivalent noise level, the most dominant tone frequency, and general noise description. Figure 1 shows one-third octave band spectra of the representative noise stimuli used in this study.

\section{Methods}

A full matrix of proximity data for MDS can be directly derived by asking a question comparing all possible pairs of objects (Borg et al., 2013). The question can be about how two objects are perceived to be similar or how much one signal is preferred over the other. A five- or nine-point Likert scale with descriptive anchors labelled as "very different" and "very similar" can be used for the similarity task.

To investigate $n$ objects, $n(n-1) / 2$ paired comparisons are required, assuming the response is symmetrical. Completing direct comparisons between all possible pairs can be a time-consuming task, especially when the number of objects under investigation is large. Alternatively, researchers can randomly or systematically choose a portion of all possible pairs to reduce the number of trials per participant. For this investigation, an incomplete cyclic test design was implemented instead of a complete set of paired comparisons to reduce the time it took to complete the comparisons (Spence and Domoney, 1974). In one session, 72 trials were administered, which is $47 \%$ of a complete set of all possible pairs (153 for 18 noise signals). Efficiency of the present test design, which is highly correlated with recovery measures, was 0.92 following calculations presented by John (1987). The cyclic design of the incomplete test was commonly used by previous studies and confirmed to have the similar reliability with the full number of paired-comparison designs (Burton, 2003; Woodcock et al., 2014). The full proximity matrix was obtained by replacing missing values with mean values for the whole matrix (Burton, 2003).

There are a number of algorithms for MDS. Although there are differences in how they process the data, all MDS algorithms aim to derive the MDS solution with an optimal number of dimensions, which have distances as close as possible to the raw proximity data (Borg et al., 2013). In MDS, the distance is a function that assigns values between two objects. Each MDS algorithm differs in how it locates objects onto perceptual maps. The algorithm can use the aggregate values before the algorithm process, or it can average the individual results after the process.

Individual differences scaling (INDSCAL), which is one of the popular MDS algorithms, assumes that all test subjects share common dimensions but have different weighting values for each of the dimensions (Carroll and Chang, 1970). Individual weight mapping then indicates how perceptual weights are different on each dimension amongst participants. In this study, INDSCAL was chosen because it can investigate individual differences but still obtain common perceptional mapping solutions. For the INDSCAL algorithm, both metric and non-metric methods are available. Metric algorithm methods assume that the

TABLE I. Description of noise signals.

\begin{tabular}{|c|c|c|c|c|}
\hline Number & Primary noise source & Noise level $\left(L_{A e q}\right)$ & Tone frequency $(\mathrm{Hz})$ & Noise description \\
\hline 1 & Condenser water pump & 50.5 & 294 & Single tone \\
\hline 2 & Radial blade pressure blower & 57.2 & 313 & Harmonics \\
\hline 3 & Water cooled screw chiller & 51 & 297 & Complex tone \\
\hline 4 & Vane axial fan & 55.3 & 313 & Complex tone \\
\hline 5 & Tube axial fan & 50.1 & 155 & Harmonics \\
\hline 6 & Heat pump & 51.5 & 120 & Single tone, fluctuating \\
\hline 7 & Outdoor condensing unit & 54.9 & 41 & Harmonics \\
\hline 8 & Digital compressor & 54 & 95 & Complex tone, fluctuating \\
\hline 9 & Heat pump & 59.4 & 47 & Harmonics, fluctuating \\
\hline 10 & Rooftop unit & 48.6 & 119 & Complex tone, fluctuating \\
\hline 11 & Heat pump & 46.2 & 719 & Complex tone \\
\hline 12 & Heat pump & 46.8 & 119 & Complex tone \\
\hline 13 & Laboratory fume hood & 46.4 & 566 & Complex tone \\
\hline 14 & Laboratory fume hood & 47.5 & 234 & Complex tone \\
\hline 15 & Screw compressor & 47 & 593 & Complex tone \\
\hline 16 & Artificially synthesized & 45.2 & $\mathrm{n} / \mathrm{a}$ & RC-38 neutral spectrum \\
\hline 17 & Artificially synthesized & 58.4 & $\mathrm{n} / \mathrm{a}$ & RC-51 neutral spectrum \\
\hline 18 & Artificially synthesized & 51.2 & $\mathrm{n} / \mathrm{a}$ & RC-38 rumbly spectrum \\
\hline
\end{tabular}




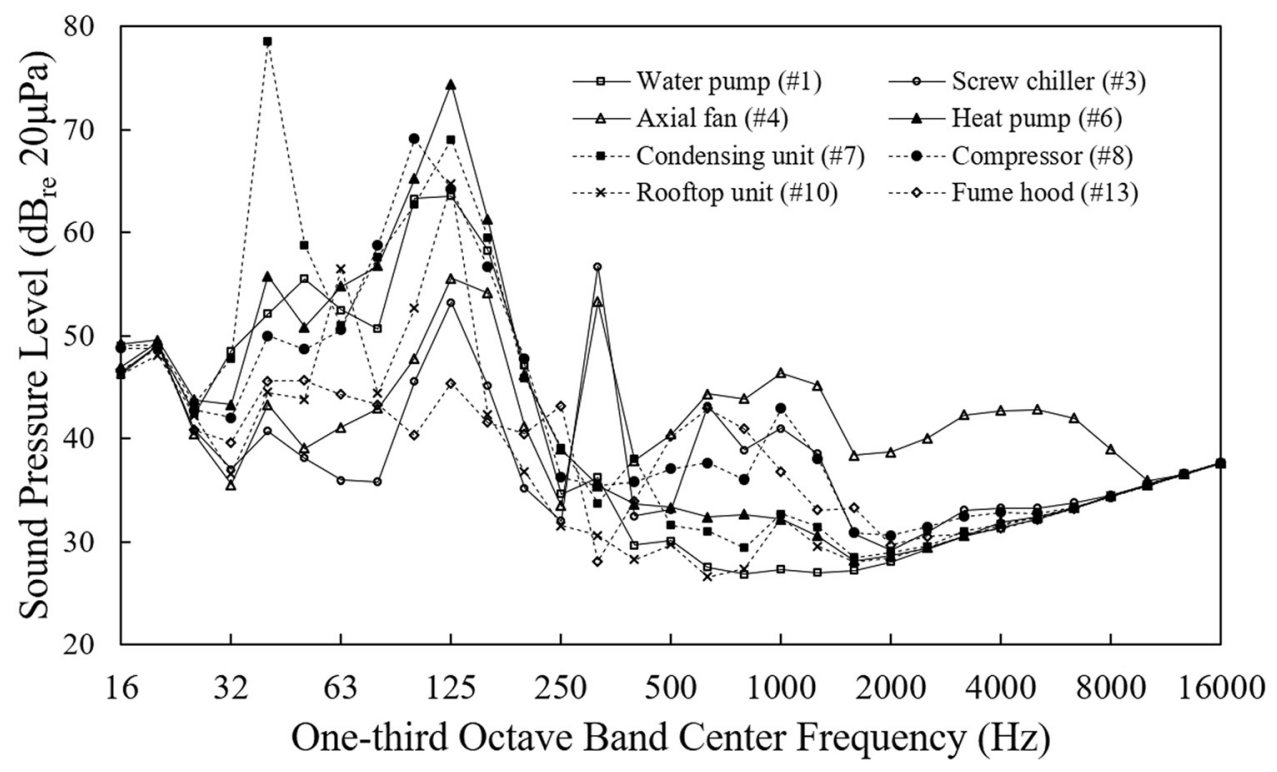

FIG. 1. One-third octave band spectra of the noise stimuli. Similar noise spectra from the same type of HVAC equipment and the artificially synthesized signals are excluded in this figure. The noise spectra are labelled with assigned numbers from Table I.

respondents' dissimilarity responses are metric data like interval and ratio level data, while a non-metric MDS algorithm uses non-metric input data like rank order. The latter does not assume any type of relationship between distance and the input data (Borg et al., 2013). In this study, metric INDSCAL was used because the collected dissimilarity data were measured at the interval level.

Once a solution is derived with the MDS algorithm, the goodness-of-fit of the solution should be evaluated. Since the MDS solution coordinates vary with a certain number of dimensions, the goodness-of-fit evaluates how close distances of the coordinate values are to the proximity data. Stress, which is the squared difference between the proximities and the distances (Kruskal, 1964), is widely used to assess the goodness-of-fit of a MDS solution. The basic equation for stress is expressed as

$$
\text { Stress }=\sqrt{\frac{\sum(d(X)-\hat{d})^{2}}{\sum d(X)^{2}}},
$$

where $d(X)$ and $\hat{d}$ indicate optimally re-scaled proximity data from participants and distances, respectively, for a configuration $X$ in dimensional spaces. The stress indicates the amount of information loss from the proximity data when the raw data are represented by the MDS solution.

A scree plot presents how the stress function changes as the number of dimensions increases (Borg et al., 2013). The lower the stress value is, the closer the MDS solution is to the original raw data. There is no strict rule to determine the minimum number of dimensions needed for a MDS solution. Previous studies recommend the "elbow" point at which point including higher dimensions may represent only random components of the data (Borg et al., 2013) or the point where the stress value is below 0.05 (Kruskal, 1964).
There is no mandated method for interpreting the meaning of each dimension from a MDS analysis. In this paper, correlation analysis of noise metrics with the MDS solutions are conducted to identify the perceptual meaning of each dimension; this method has been commonly used by other noise studies (Choe, 2001; Susini et al., 2004).

\section{Apparatus}

The subjective testing was conducted in the testing chamber at the University of Nebraska. The chamber is acoustically isolated from adjacent spaces, and its ambient background noise level is $32 \mathrm{dBA}$. The $27.8 \mathrm{~m}^{3}$ chamber is covered with carpeted floor, gypsum board, and acoustical ceiling tiles. Furnishings in the testing chamber include a chair, a computer monitor, and an indistinguishable ceiling panel with a built-in panel loudspeaker (Armstrong A-50 i-ceiling, Lancaster, PA). Refer to Lee et al. (2017) for more detailed information on the testing facility. An audio interface (Presonus AudioBox 44VSL, Baton Rouge, LA) supplied the acoustic signal to the ceiling loudspeaker and a subwoofer, which is located in a corner. The system was calibrated using a Larson Davis sound level meter model 831 (Depew, NY) at the listener's ear position to check that the noise signals were played as designed before every session. The testing was administered by a custom-coded program using a MATLAB graphic user interface (GUI; The MathWorks, Natick, MA).

\section{E. Procedure}

The test consisted of a half-hour orientation session and two half-hour main sessions, conducted on three different days. All subjects completed an orientation session with a hearing screening test. In the orientation session, participants were informed briefly about the objective and methodology of the study, and they were asked to listen to all 
noise stimuli in a random order after completing the hearing screening test. The participants also practiced the main task in the orientation session. Participants were also provided the definition of annoyance and its distinction from loudness. Annoyance was introduced as an individual's adverse reaction such as dissatisfaction, distraction, bother, and annoyance to noise (ISO/TS, 2003). To provide context for the study, the participants were asked to imagine themselves hearing the noises in their office while working. The noise sensitivity of each participant was also gathered at the orientation session by using a reduced version of the NoiSeQ questionnaire (Schutte et al., 2007).

During the main experiment, the participants completed a series of paired comparison tasks. They were asked to judge how two sound stimuli presented in a pair were similar with a nine-point Likert scale (one-very similar, nine-very different) in the first half-hour session. In the second half-hour session, the participants evaluated how much one is more annoying relatively with comparison to the other signal with a nine-point Likert scale (one-signal A more annoying, five-equally annoying, nine-signal B more annoying). The same 18 noise stimuli were used in the similarity and annoyance sessions. The response slider was designed to be snapped to the nearest integer automatically so that the subjects can provide integer responses only from one to nine. Figure 2 illustrates the main display of the program for the subjective testing.

\section{F. Results and discussion}

The consistency of participants' responses to the paired comparison tasks was checked before data analysis by using a circular triad (Parizet, 2002). The circular triad counts contradictory three paired comparison task responses among entire responses. For example, the error occurs when a subject answers signal $\mathrm{A}$ is more annoying than signal $\mathrm{B}$, signal $\mathrm{B}$ is more annoying than signal $\mathrm{C}$, and signal $\mathrm{C}$ is more annoying than signal A. One participant out of 20 was found to have an error rate of $20 \%$ and was consequently excluded from analysis. The average error rate across all other participants was $7.2 \%$ with a standard deviation of $3.4 \%$. The participants' responses were consistent and showed low error rates when compared to error rates in previous similar studies (Parizet, 2002; Woodcock et al., 2014). Kendall's coefficient of concordance $(W)$ was 0.71 . The coefficient of concordance is a measure of agreement among participants for their ratings. The coefficient value ranges from zero to one, and the higher coefficient indicates more consistent responses between the participants.

The similarity responses were analyzed with the metric INDSCAL algorithm. First, the optimal number of dimensions for the MDS solution was determined by investigating the scree plot, which plots the stress function against a number of MDS dimensions. Second, perceptual mapping with the obtained MDS solution was completed. Last, interpretation of each dimension was conducted with correlation analysis.

Figure 3 presents the scree plot of how the stress function changes as the number of dimensions increases. Even though the elbow point is not very obvious in Fig. 3, three or four dimensions appear to be the adequate choices to explain the raw data sufficiently. In this study, the MDS solution with four dimensions was selected. The normalized raw stress value with four dimensions was 0.032 , which is below 0.05 as recommended by Kruskal (1964). The normalized raw stress with three dimensions was 0.055 .

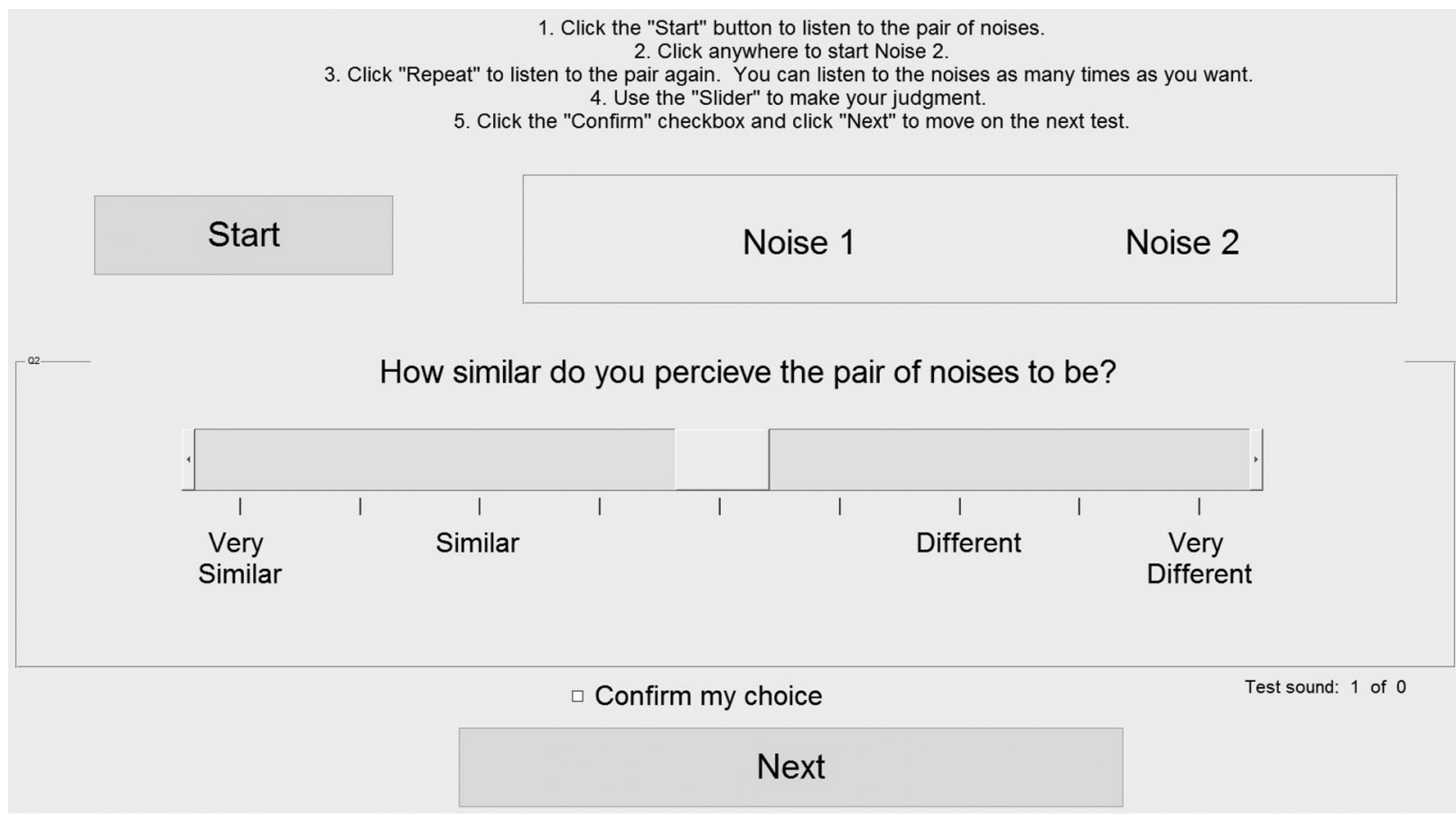

FIG. 2. Subjective testing program interface for MDS analysis. 
JASA

https://doi.org/10.1121/10.0000487

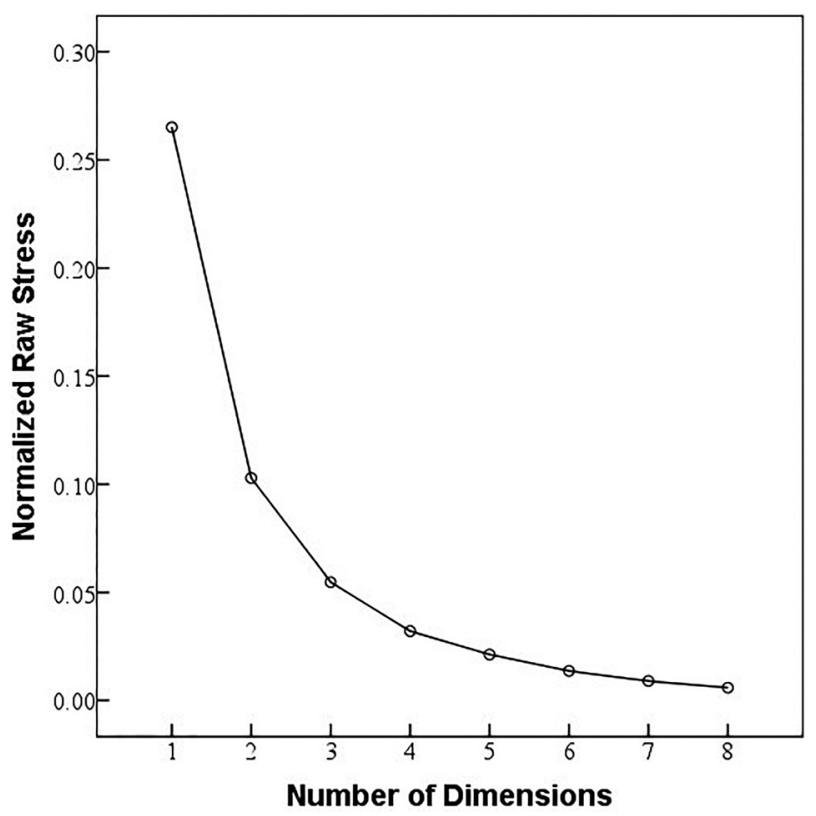

FIG. 3. Scree plot of stress as a function of the number of dimensions for the similarity task.

Figure 4 presents the derived MDS solution with four dimensions, expressed through graphs with two dimensions each. The $x$ axis is dimension 1 for all plots, while the $y$ axes are dimension 2, dimension 3 , and dimension 4 in descending order. To interpret the dimensions as perceptual structures, correlation analyses have been conducted between each dimension and assorted noise metrics describing the stimuli.

A number of noise metrics, in addition to psychoacoustic parameters like sharpness, fluctuation strength, and roughness, were calculated using $\mathrm{B}$ and $\mathrm{K}$ BK Connect sound quality module (B and K, 2019). The software calculates sharpness based on the method proposed by Aures (1985) and uses the models of Zwicker and Fastl (2007) for fluctuation strength and roughness calculations.

The standardized tonality metrics were investigated in this paper. ANSI/ASA S12.10 (ANSI/ASA, 2010) introduced tone-to-noise ratio (TNR) and prominence ratio (PR) to quantify tonality of tones in noise. Similarly, ISO 1996-2 (ISO, 2007) introduced tonal audibility $\left(\Delta L_{\mathrm{ta}}\right)$. The main difference between tonal audibility and the tonality metrics in the ANSI standard is that $\Delta L_{\mathrm{ta}}$ utilizes a linear regression to calculate masking sound levels of tones, whereas the other tonality metrics use actual broadband noise components. Widely used loudness metrics were also investigated in this study because previous studies have indicated that loudness is often the most relevant signal feature related to annoyance. Loudness levels were calculated according to ISO532-1:2017 (ISO, 2017a; Zwicker loudness) and ISO532-2:2017 (ISO, 2017b; Moore-Glasberg loudness). The Moore-Glasberg loudness is similar to the Zwicker loudness model, and it utilizes different excitation patterns and auditory filter shapes. $A$-weighted $\left(L_{\text {Aeq }}\right)$ and un-weighted $\left(L_{\text {Zeq }}\right)$ sound pressure levels (SPLs) were also calculated.

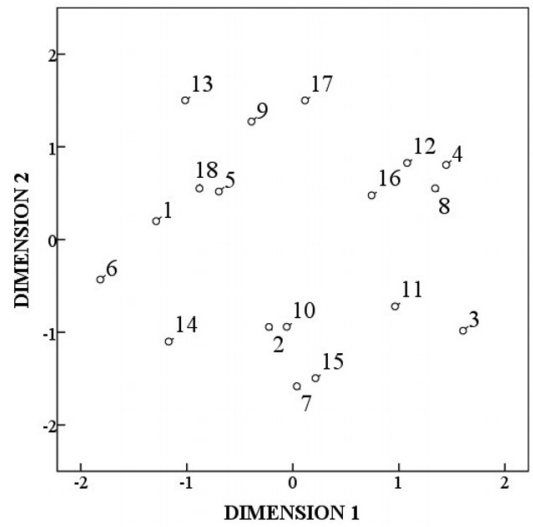

(a)

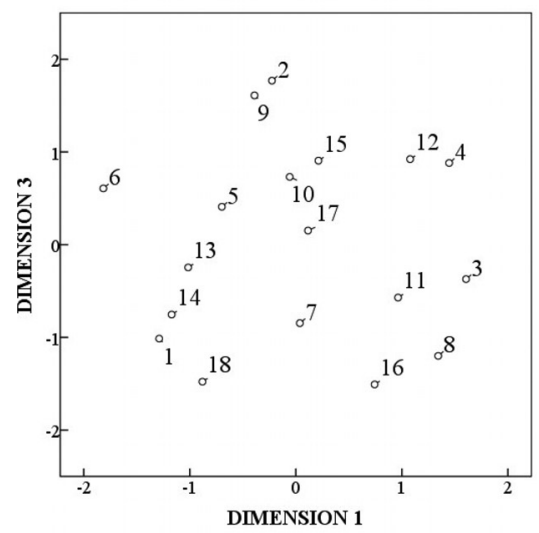

(b)

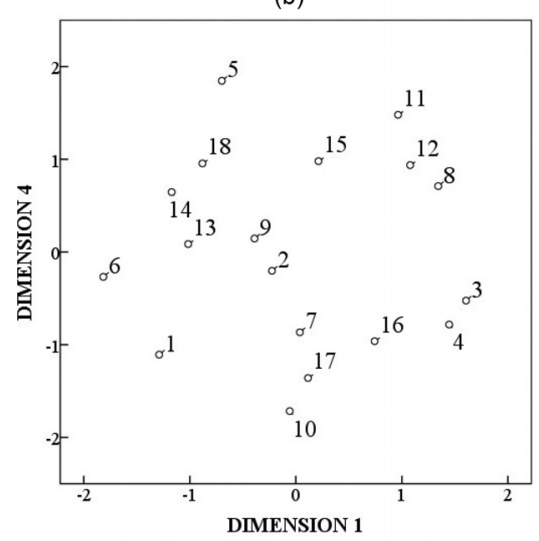

(c)

FIG. 4. Signal coordinates expressed by four dimensions of the MDS solution for the similarity task. The noise stimuli are labelled with assigned numbers from Table I. The distance of noise stimuli indicates how similar they are perceptually for specific dimensions.

There are a few noise metrics that take both loudness and tonality into account in an overall rating, primarily by adding penalty values based on tonality to the loudness level. The joint Nordic method (JNM) is standardized in ISO 1996-2 (ISO, 2007), where penalty $k$ values derived from tonal audibility are added to the $A$-weighted SPL. The tone corrected perceived noise level (PNLT) was implemented to quantify subjective annoyance to aircraft noise based on one-third octave band SPLs (Kryter and Pearsons, 1965). The sound quality indicator (SQI) was similarly implemented by the Air-Conditioning, Heating, and 
Refrigeration Institute (AHRI) to rate building mechanical product noise that contains tones (ANSI/AHRI, 2006) based on one-third octave band spectra. These combined metrics were utilized in this study as they were designed to evaluate subjective annoyance for noises with tones. Refer to Lee et al. (2017) for detailed introductions of each acoustic metric.

Table II presents all correlation coefficients between the calculated noise metrics and perceptual dimensions. Dimension 1 was highly correlated with the calculated sharpness metrics. The correlation coefficient between the sharpness measure and dimension 1 was $0.544(p=0.02)$. There was a significant correlation between dimension 2 and fluctuation strength $(\rho=-0.578, p=0.012)$ and roughness $(\rho=-0.698, p=0.001)$. Dimension 3 was highly correlated to the calculated tonality metrics; in particular, the correlation coefficient between the dimension coordinates and tonal audibility metric was 0.576 $(p=0.012)$. Dimension 4 seems to be related to the calculated loudness metrics even though the dimension coordinates are not found to be correlated at a statistically significant level with the loudness metrics; the correlation coefficients were $-0.412(p=0.09)$ with Moore-Glasberg loudness and $-0.397(p=0.10)$ with Zwicker loudness. The ranges of the metrics, which showed the highest correlation for each dimension are $0.68 \sim 1.77$ acum for sharpness, $0 \sim 2.22$ asper for roughness, $0 \sim 27.5 \mathrm{~dB}$ for tonal audibility, and $5.84 \sim 14.4$ sone for Moore-Glasberg loudness.

The results with reduced dimensions showed similar correlations with the MDS results with the four dimensions. The MDS dimensions by choosing three dimensions showed correlations with sharpness (dimension 1, Spearman $\rho=0.484$, $p=0.042$ ), roughness (dimension $2, \rho=0.681, p=0.002$ ),

TABLE II. Spearman's correlation coefficients between acoustic metrics and perceptual dimensions for the similarity task.

\begin{tabular}{lcccr}
\hline \hline & Dimension 1 & Dimension 2 & Dimension 3 & Dimension 4 \\
\hline PR & 0.342 & -0.223 & 0.038 & -0.050 \\
TNR & 0.334 & -0.095 & $0.573^{\mathrm{a}}$ & 0.058 \\
Tonal audibility & 0.258 & -0.331 & $0.576^{\mathrm{a}}$ & 0.048 \\
$\left(\Delta L_{\text {ta }}\right)$ & & & & \\
$A$-weighted SPL & -0.028 & 0.146 & 0.282 & -0.278 \\
$\left(L_{\text {Aeq }}\right)$ & & & & \\
Un-weighted SPL & -0.139 & -0.037 & -0.133 & -0.356 \\
$\left(L_{\text {Zeq }}\right)$ & & & & \\
Zwicker loudness & 0.092 & 0.063 & $0.490^{\mathrm{a}}$ & -0.397 \\
Moore-Glasberg & 0.251 & 0.003 & 0.350 & -0.412 \\
loudness & & & & \\
PNL & -0.088 & 0.086 & 0.352 & -0.340 \\
PNLT & -0.003 & 0.088 & 0.428 & -0.245 \\
JNM & 0.096 & -0.026 & 0.424 & -0.247 \\
SQI & -0.071 & 0.117 & 0.357 & -0.245 \\
Sharpness & $0.544^{\mathrm{a}}$ & -0.168 & 0.156 & -0.044 \\
Roughness & -0.113 & $-0.698^{\mathrm{b}}$ & 0.007 & -0.081 \\
Fluctuation strength & -0.113 & $-0.578^{\mathrm{a}}$ & 0.146 & -0.122 \\
\hline \hline
\end{tabular}

${ }^{\text {a }}$ Correlation is significant at the 0.05 level (two-tailed).

${ }^{\mathrm{b}}$ Correlation is significant at the 0.01 level (two-tailed). and a combination of tonality and loudness (dimension 3 ). Dimension 3 showed correlations with tonality $\left(L_{\mathrm{ta}}\right.$, $\rho=0.616, p=0.007$ ) and loudness (Zwicker loudness, $\rho=0.595, p=0.009)$. The MDS results with two dimensions only revealed correlations with roughness (dimension $1, \rho=-0.704, p=0.01$ ) and sharpness (dimension 2, $\rho=0.575, p=0.013)$. The results indicate that the psychoacoustic metrics of tonality, sharpness, and roughness were more closely related to the similarity perception than the loudness metrics.

The four perceptual dimensions found in this study are in good agreement with the perceptual dimensions discovered by Sung et al. (2017) for HVAC equipment. The dimensions in this study also correspond to the perceptual dimensions discovered by Minard et al. (2016) for HVAC noise in cars. The three perceptual dimensions found by a principal component analysis in their study were associated with unpleasantness, sharpness, and fluctuation. The unpleasantness dimension was correlated to a combination of metrics for loudness and tonal audibility. In this study, the loudness and tonality appeared as the separate dimensions of dimensions 3 and 4. Töpken and Van de Par (2019) found the six perceptual dimensions of "pleasant," "humming," "shrill," "monotone," "reverberant," and "noise-like" for fan noise. The monotone dimensions of their study are in agreement with the fluctuation dimension (dimension 2). These studies (Minard et al., 2016; Sung et al., 2017; Töpken and Van de Par, 2019) utilized a semantic differential test to identify perceptual dimensions, while the MDS was used in this study.

There are many other previous studies that show partial agreement with the four dimensions found in this study. The loudness (Oliva et al., 2017; Susini et al., 2004; Wagner et al., 2014) and tonality (More and Davies, 2010; Oliva et al., 2017; Ryherd and Wang, 2008) were found as significant predictors of annoyance or preference ratings in the sound quality studies. Paté et al. (2017) showed that the roughness is a key perceptual dimension for HVAC noise. However, the exact obtained perceptual dimensions and the interpretations vary by used noise stimuli, acoustic metrics, and subjective testing methods of the studies.

Since sharpness and roughness have been identified as one of the dominant perceptions in the MDS analysis based on the similarity data, the multiple regression model from the authors' previous studies (Lee et al., 2017) can be revised by incorporating sharpness and roughness metrics in the model in addition to the loudness and tonality metrics. To develop the annoyance regression model, the annoyance rating for each signal has to be determined. Because the subjective annoyance questions in this study followed the paired-comparison task of MDS analysis methods, relative annoyance ratings can be calculated by methods used in Parizet et al. (2005) and Woodcock et al. (2014). The relative annoyance ratings for each signal were derived by the summation of annoyance ratings for the signal in the paired comparison tasks divided by the number of tasks in which the signal was involved. 
Annoyance ratings for each signal calculated from the obtained relative annoyance judgment were used to develop an annoyance prediction model with Moore-Glasberg loudness, tonal audibility, and sharpness, as these were the three metrics that had highest correlations with the dimension data. The roughness (and fluctuation strength) was excluded in the annoyance model as it did not improve the model's annoyance prediction contrary to the finding in the MDS results. Table III presents the standard error of coefficients, standardized coefficients, and statistical significance when Moore-Glasberg loudness and tonal audibility were used (in model 1), when Moore-Glasberg loudness and sharpness were used (in model 2), and when all three metrics were included (in model 3).

The $R^{2}$ value for model 1 was 0.82 (adjusted $R^{2}$ $=0.80$ ), which is a measure of the goodness-of-fit of the linear regression, indicating that $82 \%$ of the annoyance rating variance can be explained by the Moore-Glasberg loudness and tonal audibility metrics. The root mean square error (RMSE) of model 1 was 0.586 . When including sharpness instead of tonal audibility in model 2 , the $R^{2}$ value increased to 0.88 (adjusted $R^{2}=0.87, \mathrm{RMSE}=0.469$ ). When including all three metrics for model 3 , however, the $R^{2}$ value remained the same as 0.88 (adjusted $R^{2}=0.86$, RMSE $=0.483$ ), and the tonal audibility became statistically insignificant $(p=0.637)$. Including the tonal audibility metric to model 2 does not improve the goodness-of-fit. In model 3, the coefficient for tonal audibility $(0.008)$ decreased substantially from the coefficient $(0.043)$ in model 1 , while the coefficients for sharpness remained relatively stable between model 2 and model 3.

The results indicate that the variance explained by tonal audibility and sharpness is overlapped as tonal noise at high frequencies contributes to high sharpness values also. However, it should be noted that tonality and sharpness metrics are designed to quantify different psychoacoustic perceptions. More discussion will be presented in Sec. III E for developing the accurate prediction model with these noise metrics.

\section{STUDY 2: ANNOYANCE PERCEPTION OF A MULTI-TONE COMPLEX}

The prediction models developed in study 1 show that annoyance by tonal noises from HVAC equipment can be quantified by loudness, sharpness, and tonality. Even though the tonality and sharpness contribute to annoyance individually, the combination of the two metrics fails to explain more variances of annoyance ratings. As sharpness is related to the spectral characteristics of the sound in high frequencies, the main hypothesis in this consecutive study is that revising the current tonality metric can be an alternative to improve the annoyance prediction model by including spectral and cumulative effects of multiple tones in noise.

Tonal noise from assorted building mechanical systems typically includes multiple tones in harmonic or inharmonic structures rather than a single tone. One of the biggest challenges in understanding annoyance caused by tonal noise is to include the effects of multiple tones on overall annoyance perception. Aures (1985) introduced a tonality metric capable of including multiple tones. Lee et al. (2005) modified a weighting function ( $w_{2}$ in the equation) of the Aures' tonality for better correlation with tonal strength perception by comparing perceived tonality between harmonic complexes and single tones. However, there is limited information on annoyance caused by noise with multiple tones as perceived by human occupants. Two current standards, ISO 1996-2 and ANSI S1.13 (ANSI/ASA, 2005), propose calculation methods to address tones in noise, but those methods only analyze the tones individually. The tonality metrics identified in the two standards can result in inaccurate prediction of overall annoyance, as the cumulative effect of multiple tones is not considered.

TABLE III. Linear regression model coefficients of predictors for annoyance with 95\% bias-corrected confidence intervals reported in parentheses. Standard errors are based on the 1000 bootstrap sample. Standardized $\beta$ coefficient indicates how many standard deviations the outcome (annoyance) will change per standard deviation increase in the predictor. The goodness-of-fit $\left(R^{2}\right)$ and root mean square error (RMSE) values of each model are also presented.

\begin{tabular}{|c|c|c|c|c|}
\hline & Coefficient & Standard error & $\beta$ & $p$ \\
\hline \multicolumn{5}{|l|}{ Model $1\left(R^{2}=0.82, \mathrm{RMSE}=0.586\right)$} \\
\hline Constant & 1.744 & 0.417 & & \\
\hline Moore-Glasberg loudness (sone) & $0.188(0.134,0.256)$ & 0.035 & 0.870 & 0.001 \\
\hline Tonal audibility (dB) & $0.043(0.000,0.081)$ & 0.020 & 0.251 & 0.040 \\
\hline \multicolumn{5}{|l|}{ Model $2\left(R^{2}=0.88, \operatorname{RMSE}=0.469\right)$} \\
\hline Constant & -0.252 & 0.567 & & \\
\hline Moore-Glasberg loudness (sone) & $0.201(0.149,0.269)$ & 0.033 & 0.927 & 0.002 \\
\hline Sharpness (acum) & $1.217(0.598,1.693)$ & 0.240 & 0.359 & 0.001 \\
\hline \multicolumn{5}{|l|}{ Model $3\left(R^{2}=0.88, \mathrm{RMSE}=0.483\right)$} \\
\hline Constant & -0.188 & 0.567 & & \\
\hline Moore-Glasberg loudness (sone) & $0.200(0.150,0.266)$ & 0.034 & 0.922 & 0.003 \\
\hline Tonal audibility (dB) & $0.008(-0.026,0.049)$ & 0.017 & 0.047 & 0.637 \\
\hline Sharpness (acum) & $1.115(0.647,1.481)$ & 0.258 & 0.329 & 0.007 \\
\hline
\end{tabular}


Thus, this consecutive study aims to investigate how the relative levels of each tone in a multi-tone complex contribute to overall annoyance to develop a spectral weighting function for tones in noise in terms of their contribution to annoyance. Perceptual weighting analysis is applied to compute a spectral weighting function related to overall annoyance. The performance of the derived spectral weighting function is examined against the annoyance ratings gathered from the first study reported in this paper.

\section{A. Participants}

Ten participants (six females, four males), each with at least three years of musical experience, were recruited in this study through flyers, mainly from the University of Nebraska at Omaha campus. The musically trained participants were recruited in this study to develop more accurate frequency weighting functions because the noise signals include harmonic and inharmonic tonal components. The average age of the participants was 25.8 years with a standard deviation of $9.6 \mathrm{yr}$. The average musical experience period of the participants was $14.5 \mathrm{yr}$ with a standard deviation of $12.5 \mathrm{yr}$.

The participants completed an orientation session with a hearing screening test, and all demonstrated normal hearing with thresholds better than $25 \mathrm{~dB} \mathrm{HL}$ from 125 to $8000 \mathrm{~Hz}$ for both ears. Due to extensive time commitment, ten subjects were tested; other PWA studies have found that using around 5-10 subjects can be suitable for the stated research objectives (Jesteadt et al., 2014; Leibold et al., 2007; Oberfeld et al., 2012; Oberfeld and Plank, 2011).

\section{B. Stimuli}

The signals were pink noise with added five-tone complexes. The broadband pink noise spectrum signal was generated by using the program Test Tone Generator by Esser Audio (Greensburg, PA). The overall level of the pink noise signal was $57 \mathrm{~dB}$ SPL at the listener position, and the frequency spectrum decreased at a rate of $3 \mathrm{~dB}$ per octave. The pink noise was chosen to mimic the broadband characteristics of typical HVAC noises and minimize any perceptual effects caused by the stimuli's spectra other than the added tones. Five-tone complexes were added to the pink noise to generate test signals. For the noise signals with harmonic tonal structure, tones at 125, 250, 500, 1000, and $2000 \mathrm{~Hz}$ were used. For the noise signals with inharmonic tonal structure, tones of $125,200,430,910$, and $1890 \mathrm{~Hz}$ were used; note that these tones were selected to be distinctly heard and not harmonic. The frequencies of five tones were selected to cover a common frequency range of tones generated by building mechanical equipment based on the signal recordings used in study 1 . The level of all individual tones in a reference signal was set to be $12 \mathrm{~dB}$ above the level of pink noise in that particular octave band. For the comparison signal, levels of each tone were randomly varied to be at $+4,+8,+12,+16$, or $+20 \mathrm{~dB}$ above the pink noise level. The levels of each tone were randomly chosen from a uniform probability distribution. The overall SPL of the reference signal was $63.9 \mathrm{~dB}$ SPL. The range of SPLs of the comparison signals was between 57.9 and $71.0 \mathrm{~dB}$ SPL. These levels for the individual tones were selected to exceed the threshold of tone audibility across the frequency range used (ISO, 2007), and the $4 \mathrm{~dB}$ step size was selected to be a clearly distinguishable difference from one individual tonal level to the next higher one. The sampling rate of the signals in this test was $96 \mathrm{kHz}$ and played for $2 \mathrm{~s}$. The testing facility and equipment were identical to those presented in study 1 .

\section{Methods}

A subjective study with two different structures (harmonic and inharmonic distribution) of five simultaneous tonal components in noise stimuli was conducted by using the PWA. The PWA (or molecular psychophysics) method provides the relative weights of each perceptual feature component, such as loudness, through trial-by-trial analysis (Berg and Green, 1990; Lutfi and Jesteadt, 2006). As the level or magnitude of each component is varied randomly, subjects are usually asked to choose a noise stimulus in a pair with respect to a certain aspect of perception such as loudness. Relative weights and global perception can be modeled as

$$
D=\sum_{i=1}^{m} w_{i} x_{i}+C, \quad \sum_{i=1}^{m} w_{i}=1,
$$

where $D$ is the participant's decision, $w_{i}$ is the perceptual weight for the $i$ th component, $x_{i}$ is the magnitude difference between a pair of the noise stimuli, $C$ is a constant, and $m$ is the total number of components in the noise stimulus (Leibold et al., 2007). Because relative weights are under investigation in most cases, weighting values for all of the components are normalized to sum up in total to unity. Multiple linear regression between variations of each component and responses provides the relative weighting of components.

\section{Procedures}

Participants first completed an orientation session for an hour, during which they filled out two questionnaires, one on their musical experiences and the other on their noise sensitivity based on the NoiseEQ survey (Schutte et al., 2007). In the main study, participants completed four hour-long sessions in which they were asked to choose the more annoying noise stimulus from a pair of signals, one of which was the reference signal and the other a comparison signal. The participants could listen to the reference signal and test signals as many times as they wanted. The first two sessions utilized the signals with harmonic tonal structure, while the latter two sessions utilized the signals with inharmonic tonal structure. Figure 5 presents the testing program interface shown to participants. In each session, participants completed 500 paired comparison tasks with a fixed 2-min 


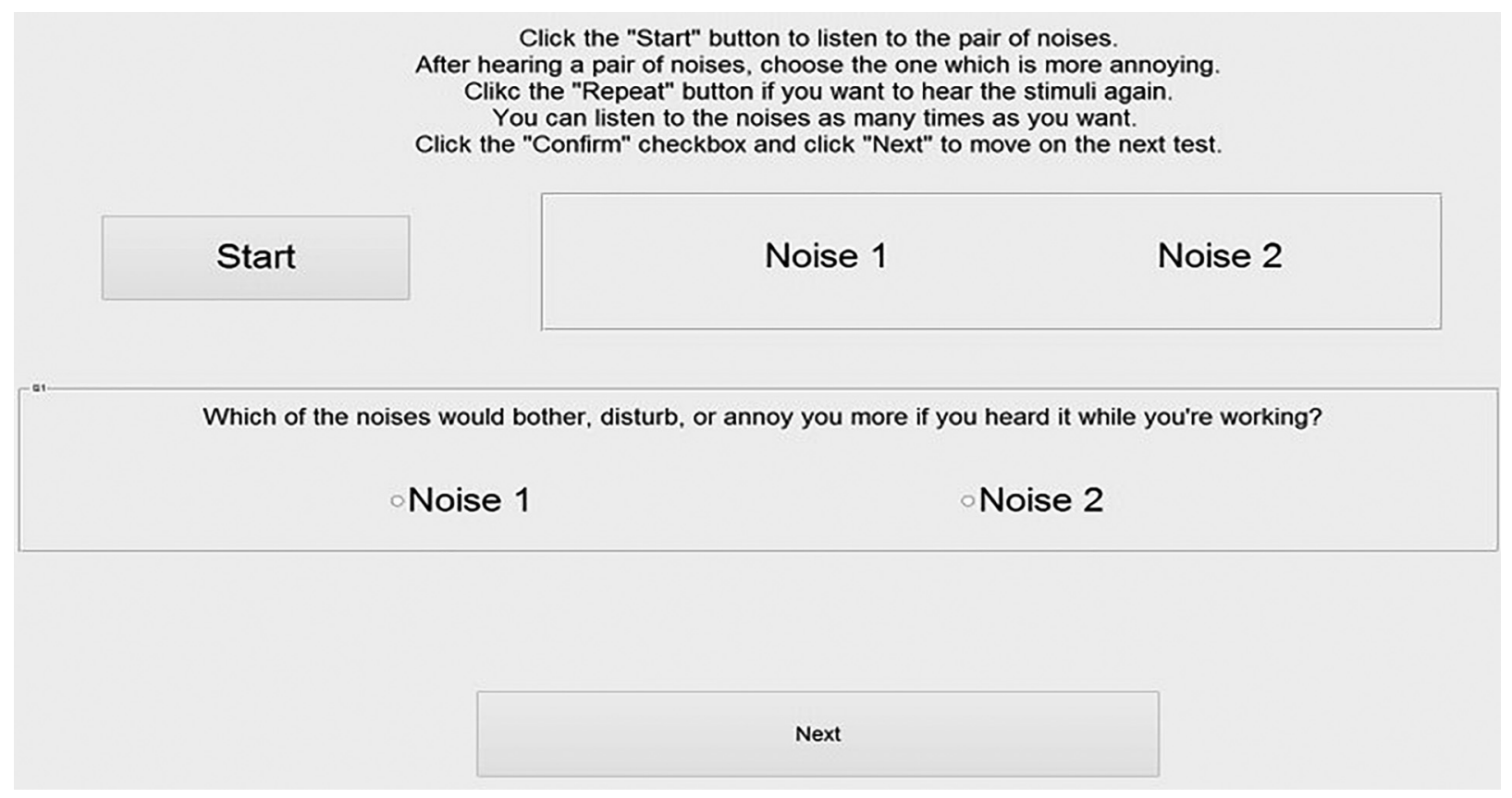

FIG. 5. Subjective testing program interface for the perceptual weighting tests.

break after every 100 trials. Each participant consequently rated a total of 2000 paired comparisons out of a total of 6250 possible.

\section{E. Results and discussions}

Prior to determining the perceptual weighting functions, the reliability of the participants' responses was examined by calculating split-half reliability (Jesteadt et al., 2014). The individual responses were divided into halves by separating odd and even numbered responses. The perceptual weights were then calculated with the odd or even numbered responses separately, 500 responses each from the harmonic structure sessions. Two perceptual weights per subject were used to calculate correlation coefficients for the split-half reliability. Generally, a coefficient value above 0.8 is considered to be reliable. All participants' showed reliability above 0.9 . Thus, all participants' perceptual weight results are included in the following analyses.

Perceptual weight functions are derived for each participant by calculating multiple linear regression models between level differences of each tone and dichotomous subjects' responses. The regression coefficients of the tones are then normalized to sum to unity. Table IV presents all perceptual weights calculated from each participant's responses.

Individual perceptual weights showed variances between the subjects. Results show that, for subjects 3,4 , and 5, there was a statistically significant relationship in the multiple regression models between the assorted tonal components and the individual participant's annoyance responses, except for the first tone component. For subject 1, the weights for all tone components were statistically significant, while only certain components were statistically significant for the other subjects. Additionally, the dominant weights were found only for the highest tone for subjects 2 and 10 , whereas lower weights were found for the highest tone for subjects 1 and 9.

Figure 6 illustrates the average perceptual weights across all participants for the harmonic and inharmonic conditions separately. The first tone component had nearly zero weight values across participants. The range of perceptual weight values across participants was wider for the tone components at higher frequencies. For both harmonic and inharmonic structures, the highest weight is observed at the highest frequency. A major difference between the harmonic and inharmonic structures was found at the second tone of 250 or $200 \mathrm{~Hz}$. The subject responses for the inharmonic structure showed higher weights to the second $(200 \mathrm{~Hz})$ tone component than the weight assigned to the $250 \mathrm{~Hz}$ tone component in the harmonic structure.

Repeated-measure factorial analysis of variance (ANOVA) was used to analyze the trend shown in Fig. 6. The two structure types and five tone components were taken as independent variables, while the individual regression coefficients were taken as dependent variables. Mauchly's test indicated that the assumption of sphericity for the repeated-measure ANOVA was violated for the effect of tone $\left[\chi^{2}(9)=49.87, p<0.001\right]$ and the structure and tone interaction $\left[\chi^{2}(9)=3.98, p<0.001\right]$. Thus, the Greenhouse-Geisser corrected degree of freedom was used. No statistically significant differences were found between the two tonal structures[harmonic or inharmonic; $F(1,9)$ $\left.=0.57, p=0.47, \eta^{2}=0.059\right]$, but there was a significant effect of tone $\left[F(1.15,10.34)=2.47, p=0.001, \eta^{2}=0.695\right]$ and a significant interaction of structure and tone $\left[F(1.37,12.29)=5.03, p=0.035, \eta^{2}=0.358\right]$ on the annoyance perceptual weights. The statistical tests indicate that the specific frequencies of the tones within a noise signal, as well as their distribution across frequency (harmonic or 
TABLE IV. Normalized perceptual weights of the five tonal components for each participant. The $p$ values of each weight, average weights across participants, and standard errors are also presented.

\begin{tabular}{|c|c|c|c|c|c|c|c|c|c|c|}
\hline \multicolumn{11}{|c|}{ Harmonic structure } \\
\hline \multirow[b]{2}{*}{ Subject } & \multicolumn{2}{|c|}{$125 \mathrm{~Hz}$ tone } & \multicolumn{2}{|c|}{$250 \mathrm{~Hz}$ tone } & \multicolumn{2}{|c|}{$500 \mathrm{~Hz}$ tone } & \multicolumn{2}{|c|}{$1 \mathrm{kHz}$ tone } & \multicolumn{2}{|c|}{$2 \mathrm{kHz}$ tone } \\
\hline & Weight & $p$ & Weight & $p$ & Weight & $p$ & Weight & $p$ & Weight & $p$ \\
\hline 1 & 0.09 & 0.00 & 0.24 & 0.00 & 0.32 & 0.00 & 0.15 & 0.00 & 0.21 & 0.00 \\
\hline 2 & 0.08 & 0.00 & 0.13 & 0.00 & 0.00 & 0.83 & 0.05 & 0.03 & 0.73 & 0.00 \\
\hline 3 & 0.03 & 0.13 & 0.15 & 0.00 & 0.30 & 0.00 & 0.25 & 0.00 & 0.27 & 0.00 \\
\hline 4 & 0.03 & 0.11 & 0.16 & 0.00 & 0.34 & 0.00 & 0.15 & 0.00 & 0.31 & 0.00 \\
\hline 5 & 0.01 & 0.62 & 0.12 & 0.00 & 0.35 & 0.00 & 0.17 & 0.00 & 0.34 & 0.00 \\
\hline 6 & 0.03 & 0.34 & 0.14 & 0.00 & 0.34 & 0.00 & 0.12 & 0.00 & 0.37 & 0.00 \\
\hline 7 & 0.07 & 0.00 & 0.03 & 0.07 & 0.29 & 0.00 & 0.14 & 0.00 & 0.47 & 0.00 \\
\hline 8 & 0.06 & 0.01 & 0.16 & 0.00 & 0.31 & 0.00 & 0.13 & 0.00 & 0.34 & 0.00 \\
\hline 9 & 0.03 & 0.33 & 0.22 & 0.00 & 0.28 & 0.00 & 0.33 & 0.00 & 0.14 & 0.00 \\
\hline 10 & 0.18 & 0.00 & 0.09 & 0.00 & 0.05 & 0.06 & 0.04 & 0.20 & 0.64 & 0.00 \\
\hline Mean & 0.06 & & 0.14 & & 0.26 & & 0.15 & & 0.38 & \\
\hline SE & 0.02 & & 0.02 & & 0.04 & & 0.03 & & 0.06 & \\
\hline
\end{tabular}

Inharmonic structure

\begin{tabular}{|c|c|c|c|c|c|c|c|c|c|c|}
\hline \multirow[b]{2}{*}{ Subject } & \multicolumn{2}{|c|}{$125 \mathrm{~Hz}$ tone } & \multicolumn{2}{|c|}{$200 \mathrm{~Hz}$ tone } & \multicolumn{2}{|c|}{$430 \mathrm{~Hz}$ tone } & \multicolumn{2}{|c|}{$910 \mathrm{~Hz}$ tone } & \multicolumn{2}{|c|}{$1.89 \mathrm{kHz}$ tone } \\
\hline & Weight & $p$ & Weight & $p$ & Weight & $p$ & Weight & $p$ & Weight & $p$ \\
\hline 1 & 0.08 & 0.00 & 0.33 & 0.00 & 0.33 & 0.00 & 0.10 & 0.00 & 0.16 & 0.00 \\
\hline 2 & 0.03 & 0.20 & 0.00 & 0.91 & 0.05 & 0.01 & 0.11 & 0.00 & 0.81 & 0.00 \\
\hline 3 & 0.02 & 0.54 & 0.34 & 0.00 & 0.23 & 0.00 & 0.11 & 0.00 & 0.30 & 0.00 \\
\hline 4 & 0.03 & 0.32 & 0.25 & 0.00 & 0.22 & 0.00 & 0.09 & 0.00 & 0.40 & 0.00 \\
\hline 5 & 0.04 & 0.13 & 0.15 & 0.00 & 0.33 & 0.00 & 0.14 & 0.00 & 0.35 & 0.00 \\
\hline 6 & 0.10 & 0.00 & 0.29 & 0.00 & 0.24 & 0.00 & 0.08 & 0.00 & 0.29 & 0.00 \\
\hline 7 & 0.01 & 0.56 & 0.17 & 0.00 & 0.14 & 0.00 & 0.05 & 0.06 & 0.62 & 0.00 \\
\hline 8 & 0.01 & 0.74 & 0.33 & 0.00 & 0.25 & 0.00 & 0.05 & 0.04 & 0.37 & 0.00 \\
\hline 9 & 0.09 & 0.01 & 0.33 & 0.00 & 0.25 & 0.00 & 0.14 & 0.00 & 0.19 & 0.00 \\
\hline 10 & 0.08 & 0.00 & 0.05 & 0.08 & 0.08 & 0.00 & 0.03 & 0.22 & 0.76 & 0.00 \\
\hline Mean & 0.05 & & 0.22 & & 0.21 & & 0.09 & & 0.43 & \\
\hline SE & 0.01 & & 0.04 & & 0.03 & & 0.01 & & 0.07 & \\
\hline
\end{tabular}

inharmonic), impact the normalized perceptual weights. As the effect sizes of partial eta-squared $\left(\eta^{2}\right)$ are large, the perceptual weights for the harmonic and inharmonic structures were developed separately instead of merging them.

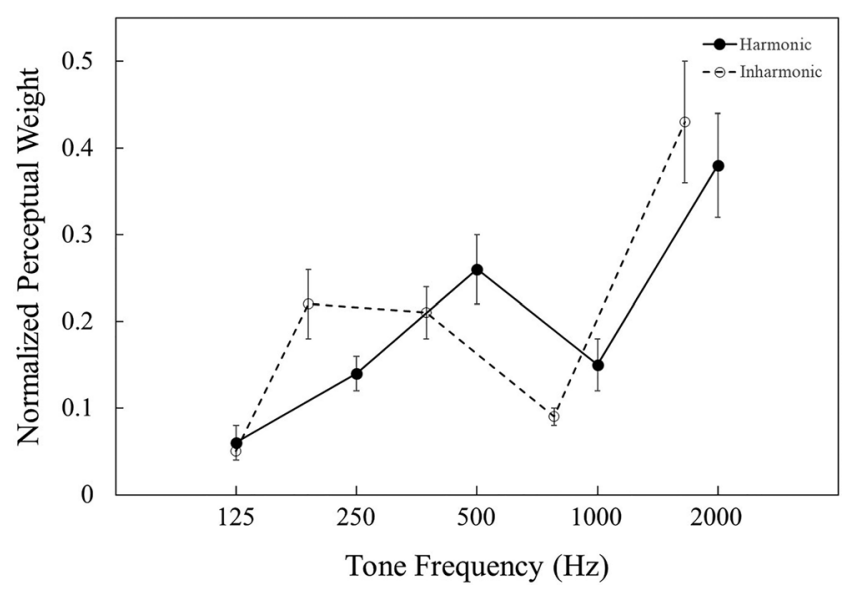

FIG. 6. The mean perceptual weights for each tone component across participants for harmonic and inharmonic structure stimuli. The perceptual weights are normalized to have a total sum of one. Error bars represent \pm 1 standard error.
The greater weights for the edges of the components (the first and last) were found in the previous studies (Jesteadt et al., 2014; Leibold et al., 2007) for loudness by using the perceptual weighting method, whereas the greater weight was found only for the last tone component in the perceptual weighting models for annoyance in this study. It is hard to determine why the models showed the low weight for the first tone component, but it can provide a clue of perceptual difference by human subjects between annoyance and loudness perception.

The obtained perceptual weighting functions have been applied to the calculation of a tonal audibility metric in an effort to predict the annoyance caused by multi-tone complexes better. The mean perceptual weights found in Table IV are adjusted to have a unity at $500 \mathrm{~Hz}$ frequency for the harmonic structure stimuli and $430 \mathrm{~Hz}$ frequency for the inharmonic structure stimuli to use fixed values across stimuli. The utilized weights are $0.23(125 \mathrm{~Hz}), 0.54(250 \mathrm{~Hz})$, $1(500 \mathrm{~Hz}), 0.58(1 \mathrm{kHz})$, and $1.46(2 \mathrm{kHz})$ for the harmonic structure stimuli and $0.24(125 \mathrm{~Hz}), 1.05(200 \mathrm{~Hz}), 1(430 \mathrm{~Hz})$, $0.43(910 \mathrm{~Hz})$, and $0.20(1.89 \mathrm{kHz})$ for the inharmonic structure stimuli. Then, as illustrated in Fig. 6, continuous 
weighting functions are determined using step-wise linear interpolations between the perceptual weights. The ISO 1996-2:2007 (ISO, 2007) annex C suggests reporting tonal audibility at the most prominent single tone, even for a complex tone stimulus. By applying the obtained perceptual weighting functions to calculate a proposed modification, here named the weighted-sum tonal audibility $\left(\Delta L_{\mathrm{ta}, w}\right)$, a better prediction of annoyance from complex tones may be available. The weighted-sum tonal audibility is defined as the metric to quantify global annoyance caused by tones and their spectral distributions.

Figure 7 illustrates the proposed process of calculating the weighted-sum tonal audibility. First, the frequency spectrum of the noise stimulus is analyzed by using the fast Fourier transform (FFT). Tonal audibility values are then calculated for all prominent tones. Then, one of two normalized perceptual weighting functions is applied, depending on whether the prevailing tone structure of the noise stimulus is harmonic or inharmonic. To determine which spectral weighting function is to be applied to noise signals, the tonal audibility values and their tone frequencies were calculated for each noise signal. If the higher tone frequencies were multiple numbers of the fundamental frequency of the signals, the harmonic weighting function was used. Otherwise, the inharmonic weighting function was applied. Last, all of the weighted tonal audibility values for each tone in the stimulus are summed to calculate a single number rating. The equation to calculate the weighted-sum tonal audibility is given by

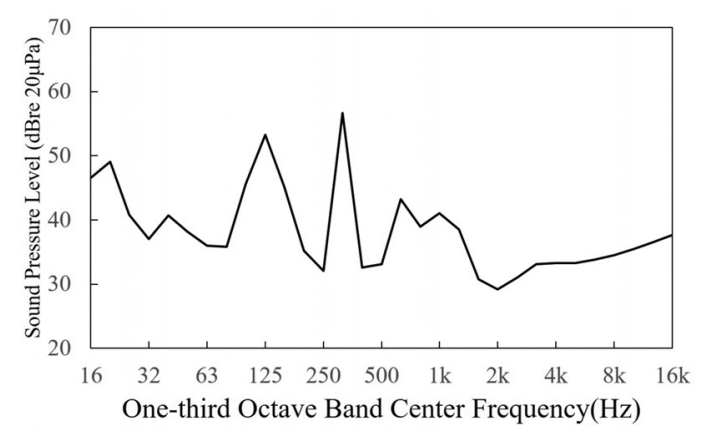

(a)

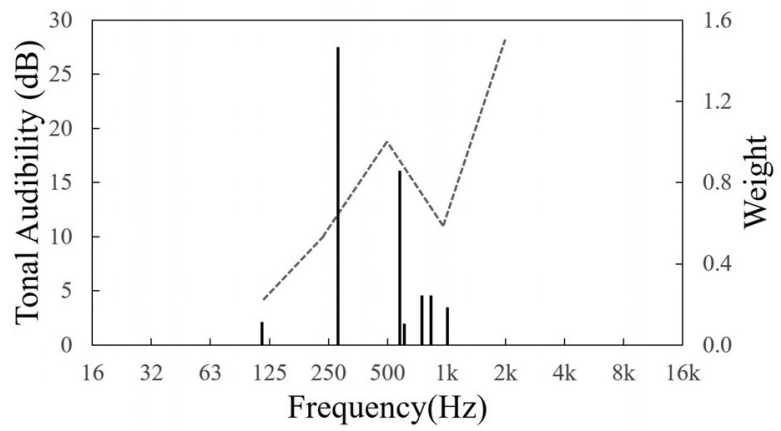

(c)

$$
\Delta L_{\mathrm{ta}, w}=\sum_{i=1}^{n} w_{i} \Delta L_{\mathrm{ta}, i}
$$

where $n$ is the number of prominent tones in the noise signal, $\Delta L_{\mathrm{ta}, i}$ is the individual tonal audibility value, and $w_{i}$ is the frequency weighting coefficient from the developed functions for each tone.

The main revision of the newly developed weightedsum tonal audibility is the summation of tonal audibility values after applying the spectral weighting functions while the tonal audibility in ISO 1996-2 (ISO, 2007) is calculated by taking a maximum value for the multiple tonal components in the spectrum. Yamaguchi et al. (2014) modified a tonality metric, named as total TNR, similarly by summing all TNR values of tonal components without considering spectral effects. They found that total TNR had a better correlation with subjective annoyance than the individual TNR value for noise from fans with multiple tones.

Table $\mathrm{V}$ presents the current standard tonal audibility and the proposed weighted-sum tonal audibility values for all noise stimuli used in study 1 . The performance of the weighted-sum tonal audibility was compared to that of the standard tonal audibility metric with the annoyance regression model developed in study 1 . The same annoyance ratings and noise stimuli were used to test the proposed weighted-sum tonal audibility. The developed annoyance models in study 1 utilized Moore-Glasberg loudness, tonal audibility, and sharpness.

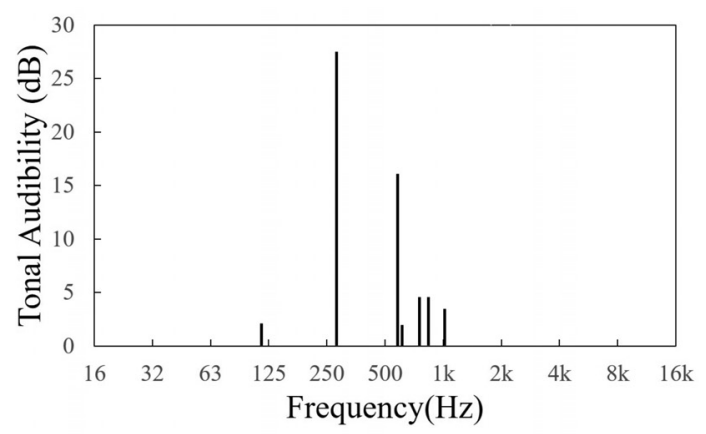

(b)

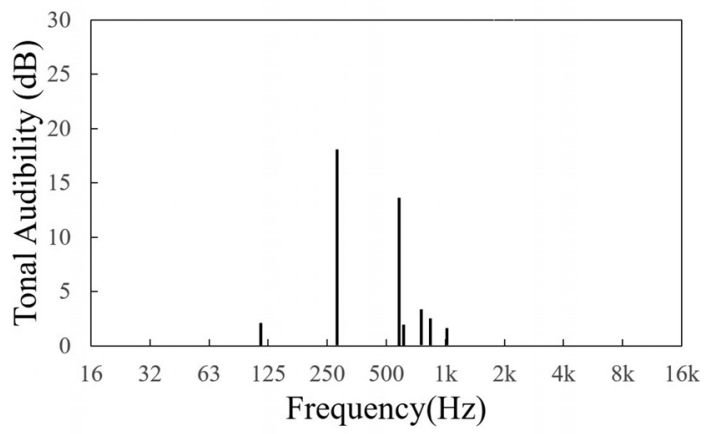

(d)

FIG. 7. Example of how to apply perceptual weighting functions. (a) Starting with a signal's one-third octave band spectrum, (b) tonal audibility is calculated for each tone extracted, then (c) the appropriate perceptual weighting function (a dashed line) is overlapped with the tonal audibility values, and (d) the result of applying the weighting function to the individual tonal audibility values. 
TABLE V. Description of noise signals with the primary noise sources, fundamental tone frequencies, and calculated acoustic metrics of Moore-Glasberg loudness, tonal audibility, and weighted-sum tonal audibility.

\begin{tabular}{|c|c|c|c|c|c|}
\hline Number & Primary noise source & $\begin{array}{l}\text { Moore-Glasberg } \\
\text { loudness (sone) }\end{array}$ & $\begin{array}{c}\text { Tone frequency } \\
(\mathrm{Hz})\end{array}$ & $\begin{array}{l}\text { Tonal audibility } \\
\qquad(\mathrm{dB})\end{array}$ & $\begin{array}{l}\text { Weighted-sum } \\
\text { tonal audibility }(\mathrm{dB})\end{array}$ \\
\hline 1 & Condenser water pump & 4.91 & 294 & 9.5 & 6 \\
\hline 2 & Radial blade pressure blower & 11.48 & 313 & 17.5 & 9.8 \\
\hline 3 & Water cooled screw chiller & 7.08 & 297 & 27.5 & 19.9 \\
\hline 4 & Vane axial fan & 11.27 & 313 & 21.7 & 15.5 \\
\hline 5 & Tube axial fan & 3.71 & 155 & 23.0 & 1.6 \\
\hline 6 & Heat pump & 5.17 & 120 & 15.6 & 5 \\
\hline 7 & Outdoor condensing unit & 14.44 & 41 & 14.0 & 6.3 \\
\hline 8 & Digital compressor & 9.30 & 95 & 11.9 & 6.1 \\
\hline 9 & Heat pump & 5.66 & 47 & 27.7 & 7.8 \\
\hline 10 & Rooftop unit & 6.75 & 119 & 23.0 & 8.6 \\
\hline 11 & Heat pump & 5.48 & 719 & 11.2 & 11.2 \\
\hline 12 & Heat pump & 5.58 & 119 & 14.7 & 11.7 \\
\hline 13 & Laboratory fume hood & 5.51 & 566 & 8.4 & 13.3 \\
\hline 14 & Laboratory fume hood & 5.75 & 234 & 11.5 & 13.9 \\
\hline 15 & Screw compressor & 6.00 & 593 & 12.4 & 14.3 \\
\hline 16 & RC-38 neutral spectrum & 4.98 & - & 0 & 0 \\
\hline 17 & RC-51 neutral spectrum & 11.91 & - & 0 & 0 \\
\hline 18 & RC-38 rumbly spectrum & 6.39 & - & 0 & 0 \\
\hline
\end{tabular}

Three regression models are compared here. Model 1 includes Moore-Glasberg loudness and tonal audibility, model 2 includes Moore-Glasberg loudness and sharpness as presented in Sec. IIE, and model 4 includes MooreGlasberg loudness and weighted-sum tonal audibility. Figure 8 illustrates regression lines from each of these models. Equation (4) presents the regression model with MooreGlasberg loudness and weighted-sum tonal audibility $\left(\Delta L_{\mathrm{ta}, w}\right)$ :

$$
\begin{aligned}
\text { Annoyance }= & 0.20 \text { Loudness }(\text { sone }) \\
& +0.08 \Delta L_{\mathrm{ta}, w}(\mathrm{~dB})+0.91 .
\end{aligned}
$$

As presented in Table VI, for model 1 without sharpness, the goodness-of-fit $\left(R^{2}\right)$ of the regression model was 0.82 (adjusted $R^{2}=0.80$, RMSE $=0.586$ ), and the change in $R^{2}$ by adding tonal audibility was only $0.06(p=0.04)$. When using the proposed weighted-sum tonal audibility metric in model 4 , the goodness-of-fit $\left(R^{2}\right)$ was improved to 0.88 (adjusted $R^{2}=0.86, \quad \mathrm{RMSE}=0.483$ ) with the change in $R^{2}$ of $0.12(p=0.002)$. The goodness-of-fit of the regression model was also 0.88 for model 2 with sharpness. Note that the $R^{2}$ values for models 2 and 4 are almost the same. Including the sharpness metric to model 4 did not improve the goodness-of-fit, mainly because the variance explained by weighted-sum tonal audibility and sharpness is overlapped as found with tonal audibility and sharpness.

The result is in agreement with the previous finding from Sung et al. (2017) that sharpness and tonality metrics together do not increase the accuracy of annoyance prediction. Similarly, Töpken and Van de Par (2019) also pointed out that the perception of spectral timbre and tonality is not distinguishable in the perceptual dimensions derived from the semantic differential for fan noise.

The new model with Moore-Glasberg loudness and weighted-sum tonal audibility was tested against noise signals and annoyance ratings from the authors' previous work (Lee and Wang, 2018), whose data were not used in developing this particular model. In the previous study, a regression model was developed using Moore-Glasberg loudness and tonal audibility to predict the annoyance responses from 20 subjects who experienced 40 artificial noise signals. For the noise signals, an individual tone at the specific frequency from $125 \mathrm{~Hz}$ to $1 \mathrm{kHz}$ was added to neural broadband noise. As the 11-point continuous scale was used for the annoyance testing in the previous study, the annoyance ratings were re-scaled to the 9-point scale by using linear transformation to compare the results with the regression model in this study.

The $R^{2}$ of the regression model using Moore-Glasberg loudness and tonal audibility was 0.948 . By replacing the tonal audibility predictor with the developed weightedsum tonal audibility, the $R^{2}$ was improved to 0.953 . Even though the improvement was not substantial, the improved performance of the model validates the finding in this study; the application of the proposed weighting function to calculate tonality can lead to slightly better prediction of annoyance from tonal noise signals. Figure 9 presents the two regression models with the best-fit coefficients for the annoyance ratings of the 40 previous noise signals and the coefficients from Eq. (4) with MooreGlasberg loudness and weighed-sum tonal audibility. The regression model from Eq. (4) shows a trend of overestimating the annoyance rating for less annoying noise signals as compared to the best-fit regression model but does 


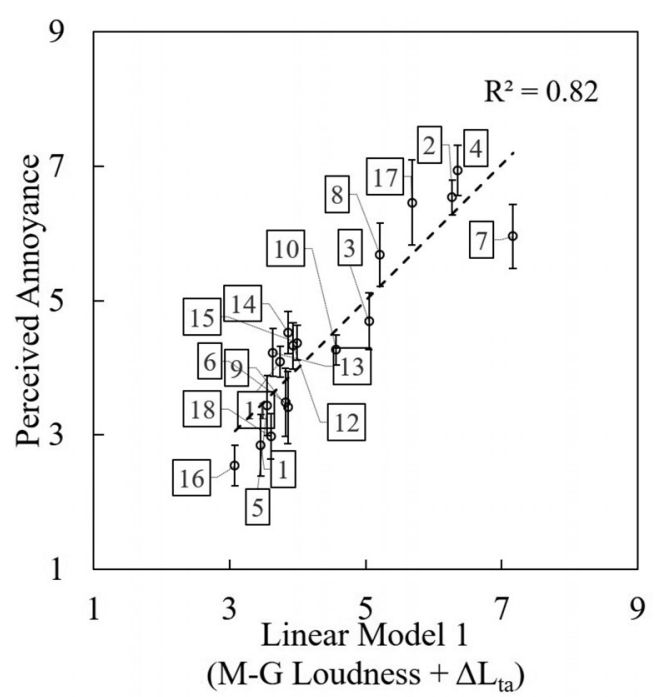

(a)

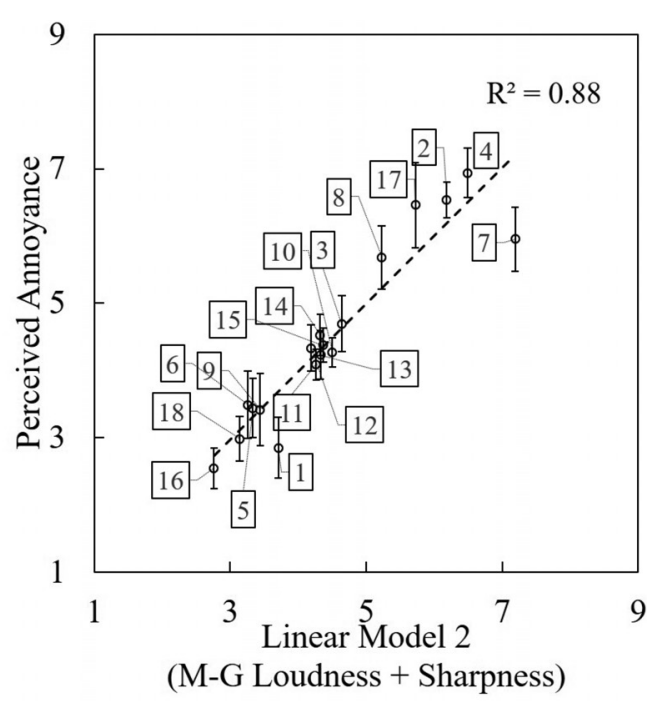

(b)

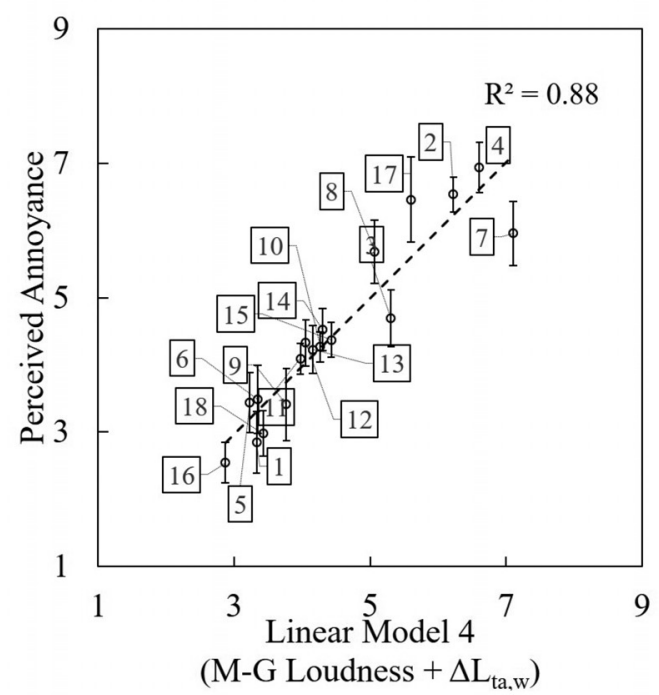

(c)

FIG. 8. Averages (mark) and standard deviations (error bar) of the annoyance ratings across participants for each noise stimulus from study 1. The dashed lines represent the perfect match between the measured annoyance ratings and the regression models with Moore-Glasberg loudness and (a) tonal audibility (model $1, R^{2}=0.82$ ), (b) tonal audibility and sharpness (model $2, R^{2}=0.88$ ), (c) weighted-sum tonal audibility (model $4, R^{2}=0.88$ ). The noise stimuli are labelled with assigned numbers (in boxes) from Table V.

a reasonable job of predicting the relative annoyance from those signals.

\section{CONCLUSIONS}

This paper presents two studies aimed at understanding other characteristics of tonal noise from HVAC systems, in addition to loudness and tonality, and testing whether models that predict annoyance are significantly improved by incorporating those additional aspects. With the first investigation using MDS, paired comparison tasks were conducted to gather both similarity and annoyance data. The MDS test results show that the four perceptual dimensions were related to the tonality, loudness, roughness, and sharpness of the noise stimulus. The study utilized the incomplete cyclic test design to reduce the number of paired comparisons, which can influence the perceptual dimension results. A revised annoyance prediction model that was based on loudness and sharpness metrics showed better agreement against gathered annoyance ratings than the model developed by the authors in the previous study with loudness and tonality metrics (Lee et al., 2017).

The second study involved PWA to investigate how multi-tone complexes affect overall annoyance. Noise stimuli with five-tone complexes at specific frequencies between $125 \mathrm{~Hz}$ to $2 \mathrm{kHz}$ were artificially generated for subjective testing to obtain the perceptual weighting function of complex tones. Both harmonic and inharmonic structures of tones were utilized. A weighted-sum tonal audibility metric is proposed that applies the results from the perceptual weighting analysis as a spectral weighting function. The performance of the newly developed metric showed better 
TABLE VI. Linear regression model coefficients of predictors for annoyance with $95 \%$ bias-corrected confidence intervals reported in parentheses from study 1 and the weighted-sum tonal audibility. Standard errors are based on the 1000 bootstrap sample. Standardized $\beta$ coefficient indicates how many standard deviations the outcome (annoyance) will change per standard deviation increase in the predictor. The goodness-of-fit $\left(R^{2}\right)$ and RMSE values of each model are also presented.

\begin{tabular}{|c|c|c|c|c|}
\hline & Coefficient & Standard error & $\beta$ & $p$ \\
\hline \multicolumn{5}{|l|}{ Model $1\left(R^{2}=0.82, \mathrm{RMSE}=0.586\right)$} \\
\hline Constant & 1.744 & 0.417 & & \\
\hline Moore-Glasberg loudness (sone) & $0.188(0.134,0.256)$ & 0.035 & 0.870 & 0.001 \\
\hline Tonal audibility $(\mathrm{dB})$ & $0.043(0.000,0.081)$ & 0.020 & 0.251 & 0.040 \\
\hline \multicolumn{5}{|l|}{ Model $2\left(R^{2}=0.88\right.$, RMSE $\left.=0.469\right)$} \\
\hline Constant & -0.252 & 0.567 & & \\
\hline Moore-Glasberg loudness (sone) & $0.201(0.149,0.269)$ & 0.033 & 0.927 & 0.002 \\
\hline Sharpness (acum) & $1.217(0.598,1.693)$ & 0.240 & 0.359 & 0.001 \\
\hline \multicolumn{5}{|l|}{ Model $4\left(R^{2}=0.88\right.$, RMSE $\left.=0.483\right)$} \\
\hline Constant & 0.909 & 0.442 & & \\
\hline Moore-Glasberg loudness (sone) & $0.197(0.149,0.263)$ & 0.032 & 0.908 & 0.000 \\
\hline Weighted-sum tonal audibility (dB) & $0.081(0.039,0.131)$ & 0.023 & 0.347 & 0.002 \\
\hline
\end{tabular}

annoyance prediction than using the traditional tonal audibility metric, as the new metric accounts for multiple tonal components by applying the spectral weighting functions, while the current metric only retains a maximum value after calculation of individual tones. A revised annoyance regression model using the two metrics of Moore-Glasberg loudness and the weighted-sum tonal audibility showed similar prediction performance to the regression model from the first study that used Moore-Glasberg loudness and sharpness. The new prediction model was validated using noise signals and annoyance ratings from previous work that were not a part of the model development.

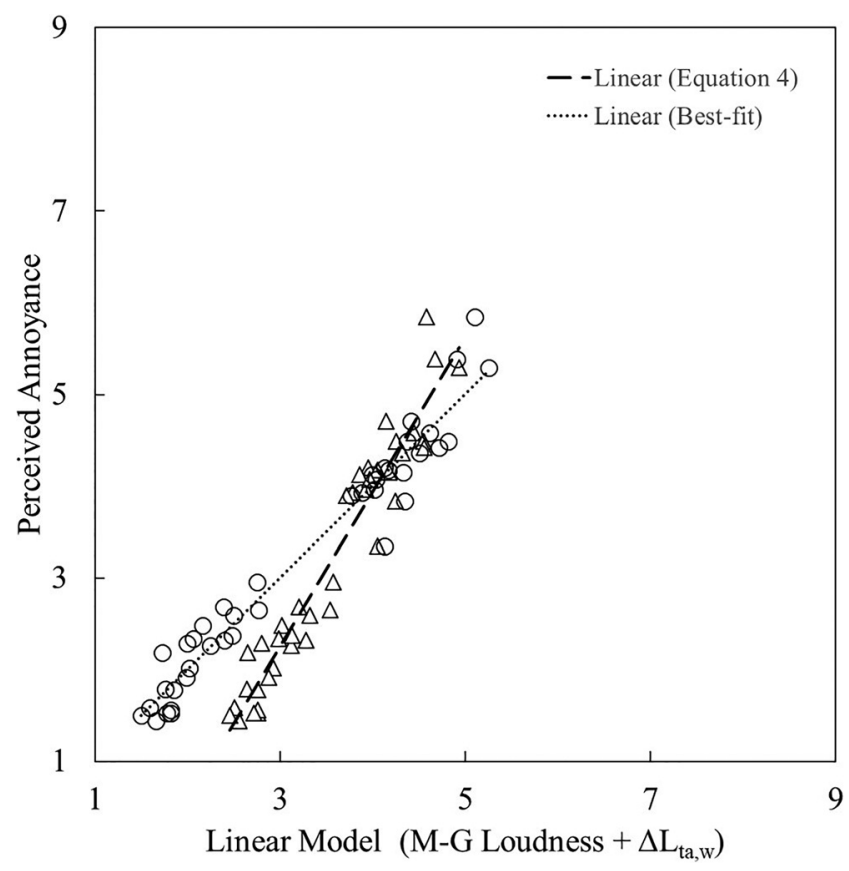

FIG. 9. Average of the annoyance ratings for each noise stimulus used in the authors' previous work (Lee and Wang, 2018) plotted against the proposed linear regression model of annoyance from Eq. (4) (triangle marks) and the best-fit regression model (circle marks). The models are based on Moore-Glasberg loudness and weighted-sum tonal audibility.
The research presented here clearly indicates that, compared to accounting only for tonality of the most prevailing tone and signal loudness, predictions of annoyance from noise produced by building mechanical systems are improved by also considering the frequencies and the structure of other tones in the noise signal. The two prediction models from the studies presented in this paper, one with loudness and sharpness metrics and one based on loudness and weighted-sum tonal audibility metrics, have similar prediction performance. Adding sharpness to the model with weighted-sum tonal audibility does not result in further improvement, though, likely because the two metrics account similarly for the spectral content of the noise. The tonal noises also show a tendency of having high sharpness values as the tonal and their harmonic components produce sharper high-frequency sounds. Further study is required with the noise signals of broadband high-frequency dominant sounds to test whether sharpness and weighted-sum tonal audibility can contribute to annoyance independently.

The proposed weighted-sum tonal audibility does have some limitations. Deciding to use the perceptual weighting function for a harmonic or inharmonic structure is rather subjective because, in many noise signals, harmonic and inharmonic tones are blended in the same stimuli. Also, the suggested weighting functions use a linear interpolation at frequencies between the tones examined in this study. More testing with assorted scenarios of other frequency and sound level ranges should be conducted to understand how such weighting functions may vary. The effect of loudness variations on annoyance in the perceptual weighting study has not been investigated in this paper. It should also be noted that the musically trained participants were recruited for the perceptual weighting study. The perceptual weight with more test subjects without any musical training is suggested for future research to validate the findings.

Another limitation of this study is that all findings are based on laboratory experiments. Even though subjective testing in the laboratory has assorted advantages to test research hypotheses, further work is recommended to 
validate the findings with in situ measurements. Continuing research should furthermore investigate effects of timefluctuating characteristics of tones on annoyance. The noise signals used in this test did not exhibit a wide range of fluctuation properties of tones in noise and, consequently, did not find any statistically significant effect of tone fluctuation characteristics on annoyance. Or, the tested descriptors in this study are not suitable to quantify fluctuating characteristics of the noises from building mechanical systems. A new descriptor may need to be developed in the future.

\section{ACKNOWLEDGMENTS}

The authors thank Mr. Jerry Lilly for providing the audio recordings used in this study and Dr. Walt Jesteadt and Dr. Erica Ryherd for valuable advice regarding research design and analysis.

ANSI/AHRI (2006). 1140-2006, Sound Quality Evaluation Procedures for Air-Conditioning and Refrigeration Equipment (Air-Conditioning, Heating, and Refrigeration Institute, Arlington, VA).

ANSI/ASA (2005). S1.13, Measurement of Sound Pressure Levels in Air (Acoustical Society of America, Melville, NY).

ANSI/ASA (2010). S12.10-2010/Part1, Acoustics-Measurement of Airborne Noise Emitted by Information Technology and Telecommunications Equipment-Part 1: Determination of Sound Power Level and Emission Sound Pressure Level (Acoustical Society of America, Melville, NY).

Aures, W. (1985). "Procedure for calculating the sensory euphony of arbitrary sound signals," Acustica 59(2), 130-141.

B and K (2019). BK Connect Data Processing (Brüel and Kjær, Nærum, Denmark).

Berg, B. G., and Green, D. M. (1990). "Spectral weights in profile listening," J. Acoust. Soc. Am. 88(2), 758-766.

Berglund, B., Hassmén, P., and Preis, A. (2002). "Annoyance and spectral contrast are cues for similarity and preference of sounds," J. Sound Vib. 250(1), 53-64.

Bisping, R. (1997). "Car interior sound quality: Experimental analysis by synthesis," Acta Acust. Acust. 83(5), 813-818.

Blazier, W. E., Jr. (1981). "Revised noise criteria for application in the acoustical design and rating of HVAC systems," Noise Control Eng. 16(2), 64-73.

Borg, I., Groenen, P. J. F., and Mair, P. (2013). Applied Multidimensional Scaling (Springer, New York, NY).

Bradley, D. T., and Wang, L. M. (2010). "Optimum absorption and aperture parameters for realistic coupled volume spaces determined from computational analysis and subjective testing results," J. Acoust. Soc. Am. 127(1), 223-232.

Burton, M. L. (2003). "Too many questions? The uses of incomplete cyclic designs for paired comparisons," Field Methods 15(2), 115-130.

Carroll, J. D., and Chang, J.-J. (1970). "Analysis of individual differences in multidimensional scaling via an $n$-way generalization of "EckartYoung' decomposition," Psychometrika 35(3), 283-319.

Choe, B. (2001). "Nonmetric multidimensional scaling of complex sounds," Ph.D. dissertation, Universität Oldenburg, Oldenburg, Germany.

Dittrich, K., and Oberfeld, D. (2009). "A comparison of the temporal weighting of annoyance and loudness," J. Acoust. Soc. Am. 126(6), 3168-3178.

Grey, J. M., and Gordon, J. W. (1978). "Perceptual effects of spectral modifications on musical timbres," J. Acoust. Soc. Am. 63(5), 1493-1500.

Hasting, A., Lee, K. H., Davies, P., and Surprenant, A. M. (2003). "Measurement of the attributes of complex tonal components commonly found in product sound," Noise Control Eng. J. 51(4), 195-209.

Hellman, R. P. (1985). "Perceived magnitude of two-tone-noise complexes: Loudness, annoyance, and noisiness," J. Acoust. Soc. Am. 77(4), 1497-1504.
ISO (2007). 1996-2:2007, Acoustics-Description, Measurement and Assessment of Environmental Noise - Part 2: Determination of Sound Pressure Levels (International Organization for Standardization, Geneva, Switzerland).

ISO (2017a). 532-1:2017, Acoustics—Methods for Calculating LoudnessPart 1: Zwicker Method (International Organization for Standardization, Geneva, Switzerland).

ISO (2017b). 532-2:2017, Acoustics—Methods for Calculating LoudnessPart 2: Moore-Glasberg Method (International Organization for Standardization, Geneva, Switzerland).

ISO/TS (2003). 15666, Assessment of Noise Annoyance by Means of Social and Socio-Acoustic Surveys (International Organization for Standardization, Geneva, Switzerland).

Jesteadt, W., Valente, D. L., Joshi, S. N., and Schmid, K. K. (2014). "Perceptual weights for loudness judgments of six-tone complexes," J. Acoust. Soc. Am. 136(2), 728-735.

John, J. A. (1987). Cyclic Designs (Springer, New York, NY).

Kruskal, J. B. (1964). "Nonmetric multidimensional scaling: A numerical method," Psychometrika 29(2), 115-129.

Kryter, K. D., and Pearsons, K. S. (1965). "Judged noisiness of a band of random noise containing an audible pure tone," J. Acoust. Soc. Am. 38(1), 106-112.

Lee, J., Francis, J. M., and Wang, L. M. (2017). "How tonality and loudness of noise relate to annoyance and task performance," Noise Control Eng. J. 65(2), 71-82.

Lee, J., and Wang, L. M. (2018). "Development of a model to predict the likelihood of complaints due to assorted tone-in-noise combinations," J. Acoust. Soc. Am. 143(5), 2697-2707.

Lee, K. H., Davies, P., and Surprenant, A. M. (2005). "Tonal strength of harmonic complex tones in machinery noise," J. Acoust. Soc. Am. 118(3), 1921-1921.

Leibold, L. J., Tan, H., Khaddam, S., and Jesteadt, W. (2007). "Contributions of individual components to the overall loudness of a multitone complex," J. Acoust. Soc. Am. 121(5), 2822-2831.

Lutfi, R. A., and Jesteadt, W. (2006). "Molecular analysis of the effect of relative tone level on multitone pattern discrimination," J. Acoust. Soc. Am. 120(6), 3853-3860.

Minard, A., Boussard, P., and Lambourg, C. (2016). "Perceptual evaluation of the sound quality of car hvac systems," in Proc. Inter-Noise 2016, Institute of Noise Control Engineering, Hamburg, Vol. 253, pp. 7105-7112.

More, S., and Davies, P. (2010). "Human responses to the tonalness of aircraft noise," Noise Control Eng. J. 58(4), 420-440.

Oberfeld, D., Heeren, W., Rennies, J., and Verhey, J. L. (2012). "Spectrotemporal weighting of loudness," PloS One 7(11), e50184.

Oberfeld, D., and Plank, T. (2011). "The temporal weighting of loudness: Effects of the level profile," Atten. Percept. Psychophys. 73(1), 189-208.

Oliva, D., Hongisto, V., and Haapakangas, A. (2017). "Annoyance of lowlevel tonal sounds-Factors affecting the penalty," Build. Environ. 123, 404-414.

Parizet, E. (2002). "Paired comparison listening tests and circular error rates," Acta Acust. Acust. 88(4), 594-598.

Parizet, E., Hamzaoui, N., and Sabatie, G. (2005). "Comparison of some listening test methods: A case study," Acta Acust. Acust. 91(2), 356-364. Paté, A., Lavandier, C., Minard, A., and Le Griffon, I. (2017). "Perceived unpleasantness of aircraft flyover noise: Influence of temporal parameters," Acta Acust. Acust. 103(1), 34-47.

Ryherd, E. E., and Wang, L. M. (2008). "Implications of human performance and perception under tonal noise conditions on indoor noise criteria," J. Acoust. Soc. Am. 124(1), 218-226.

Schutte, M., Marks, A., Wenning, E., and Griefahn, B. (2007). "The development of the noise sensitivity questionnaire," Noise Health 9(34), 15-24.

Spence, I., and Domoney, D. W. (1974). "Single subject incomplete designs for nonmetric multidimensional scaling," Psychometrika 39(4), 469-490.

Sung, W., Davies, P., and Bolton, J. S. (2017). "Results of a semantic differential test to evaluate HVAC\&R equipment noise," in Proc. InterNoise 2017, Institute of Noise Control Engineering, Hong Kong, Vol. 255, pp. 2390-2398.

Susini, P., McAdams, S., Winsberg, S., Perry, I., Vieillard, S., and Rodet, X. (2004). "Characterizing the sound quality of air-conditioning noise," Appl. Acoust. 65(8), 763-790. 
Töpken, S., Scheel, H., Verhey, J. L., and Weber, R. (2018). "Quantification of preference relevant sound characteristics of multi-tone sounds based on the differences between loudness judgments and preference evaluations,” Acta Acust. Acust. 104(1), 153-165.

Töpken, S., and Van de Par, S. (2019). "Perceptual dimensions of fan noise and their relationship to indexes based on the specific loudness," Acta Acust. Acust. 105(1), 195-209.

Töpken, S., Verhey, J. L., and Weber, R. (2015). "Perceptual space, pleasantness and periodicity of multi-tone sounds," J. Acoust. Soc. Am. 138(1), 288-298.

Wagner, V., Enigk, H., Beitz, T., and Kallus, K. W. (2014). "Subjective and objective evaluation of the air conditioning sound," J. Ergonomics 4(2), 1000131.
Wang, Y., Liu, S., Dong, Y., and Cai, J. (2015). "Effects of acoustic characteristics on annoyance of aircraft flyover noise," Noise Control Eng. J. 63(3), 279-286.

Woodcock, J. S., Moorhouse, A. T., and Waddington, D. C. (2014). "A multidimensional evaluation of the perception and annoyance caused by railway induced groundborne vibration," Acta Acust. Acust. 100(4), 614-627.

Yamaguchi, T., Minorikawa, G., and Kihara, M. (2014). "Study on evaluation method of the pure tone for small fan," in Proc. Inter-Noise 2014, Institute of Noise Control Engineering, Melbourne, Vol. 249, pp. 1629-1633.

Zwicker, E., and Fastl, H. (2007). Psychoacoustics: Facts and Models, 3rd ed. (Springer, New York, NY). 